\title{
Clinical profile of Otomycosis: a hospital based study at central terrain region of Nepal
}

\author{
Lageju N1, Shahi SC1, Goil NK \\ Department of ENT, Janaki Medical College \\ Ramdaiya, Janakpur, Nepal
}

${ }^{1}$ Assistant Prof, ENT Department, Janaki Medical College, Janakpur

\begin{abstract}
Background and Objectives: Otomycosis is the fungal infection of ear with some complications involving middle ear cavity and mastoid cavity. It is one of commonly encountered problem in otolaryngology clinics. It is commonly present in hot, humid with moisture, high temperature. So, this research is to study the clinical profile of otomycosis in central terrain region of Nepal.

Material and Methods: The study was conducted in department of ENT- head and neck surgery in Janaki medical college and teaching hospital from August 2015 to June 2016. All the clinically diagnosed cases were enrolled in the study with typical symptoms and characteristics fungal debris in the external auditory canal (EAC). All the data regarding age, sex, occupation, presenting complaints, type of fugal debris, presence of acute otitis externa, findings of tympanic membrane (TM) taken.
\end{abstract}

Results: Total of 77 patients were enrolled. Among them $27(35.1 \%)$ were male and $50(64.9 \%)$ were female. The most common presenting complaint is itching followed by earache, ear discharge, hearing loss. Itching was present in $77.9 \%$ of the cases followed by earache in $72.7 \%$, aural fullness in 29\%, ear discharge in $46.8 \%$ and hearing loss in $31.2 \%$. Based on type of fungal debris on otoscopy, blackish was the commonest with frequency of 38 patients $(49.4 \%)$ followed by whitish debris in 27 patients (35.1\%) and yellowish among 12 patients (15.6\%).

Conclusion: Otomycosis is one of the most common presenting problems in otorhinolaryngology OPD. Females are affected more. Aspergillus niger implicated the most and ear itching is the most common presenting symptom.

Key Words: Otomycosis, Fungal debris, Aspergillus, Candida, ENT

\section{INRODUCTION}

Otomycosis is the fungal infection of ear with some complications involving middle ear cavity [1] and mastoid cavity [2]. Otomycosis is a superficial mycotic infection of the outer ear canal. The infection may be either subacute or acute and is characterized by inflammation, pruritus, scaling, and severe 
discomfort. The mycosis results in inflammation, superficial epithelial exfoliation, masses of debris containing hyphae, suppuration, and pain.

It is one of commonly encountered problem in otolaryngology clinics. It is commonly present in hot, humid with moisture, high temperature, the entrance of water into the ear during swimming or sweat secretions, increased use of topical antibiotics, weak immune function [3]. Molds and yeasts are common in the auditory canals of otomycosis patients. The molds mostly isolated from the ear are Aspergillus niger, Aspergillus fumigatus, Aspergillus flavus, Aspergillus nidulans, Aspergillus terreus, Mucorspecies, and Penicillium species [4] and yeast commonly candida species implicated. Common presentations of otomycosis are ear itching, ear discharge, earache, aural fullness and less commonly decreased hearing [5]. On examination aspergillus niger appear as blackish, aspergillus flavus appear as yellowish and candida as whitish creamy colonies which also referred as wet newspaper appearance. Pathologically, fungal infection of the EAC and TM lead to small intradermal abscess. Hemorrhagic granulations can cause thrombosis of adjacent blood vessels leading to avascular necrosis and perforation of TM [6]. Very less literature are found regarding the clinical profile of otomycosis in Nepal and almost nil literature are available in terrain region of Nepal. So this research is carried to study the clinical profile of otomycosis in central terrain region of Nepal

\section{MATERIALS AND METHODS}

The study was conducted in department of ENT- head and neck surgery in Janaki medical college and teaching hospital from August 2015 to June 2016. All the clinically diagnosed cases were enrolled in the study with typical symptoms and characteristics fungal debris in the EAC. All the data regarding age, sex, occupation, presenting complaints, type of fugal debris, presence of acute otitis externa, findings of TM were taken and analysed. The data is presented in result section.

\section{RESULTS}

Total of 77 patients were enrolled in the study. Among them $27(35.1 \%)$ were male and $50(64.9 \%)$ were female.

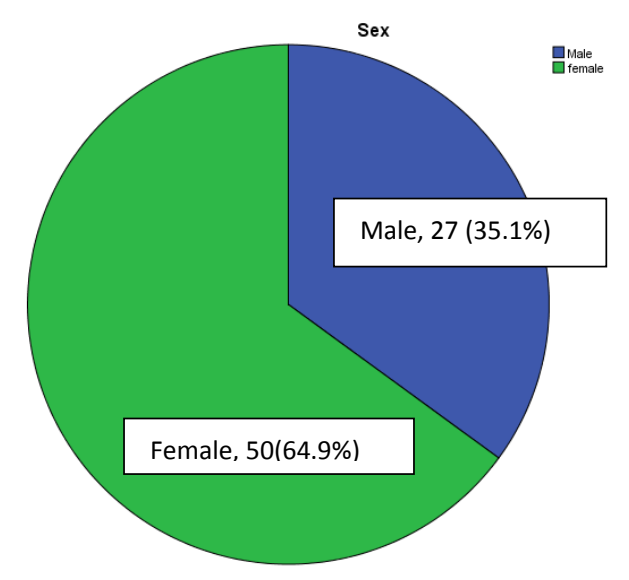

\section{Figure1: Sex distribution $(n=77)$}

Taking symptomatology under consideration the most common presenting complaint is itching followed by earache, ear discharge, hearing loss.Itching was present in $77.9 \%$ of the cases followed by earache in $72.7 \%$, aural fullness in $29 \%$, ear discharge in $46.8 \%$ and hearing loss in $31.2 \%$.

Among patients with hearing loss conductive hearing loss was present in 19 patients and sensori-neural hearing loss in 5 patients. 


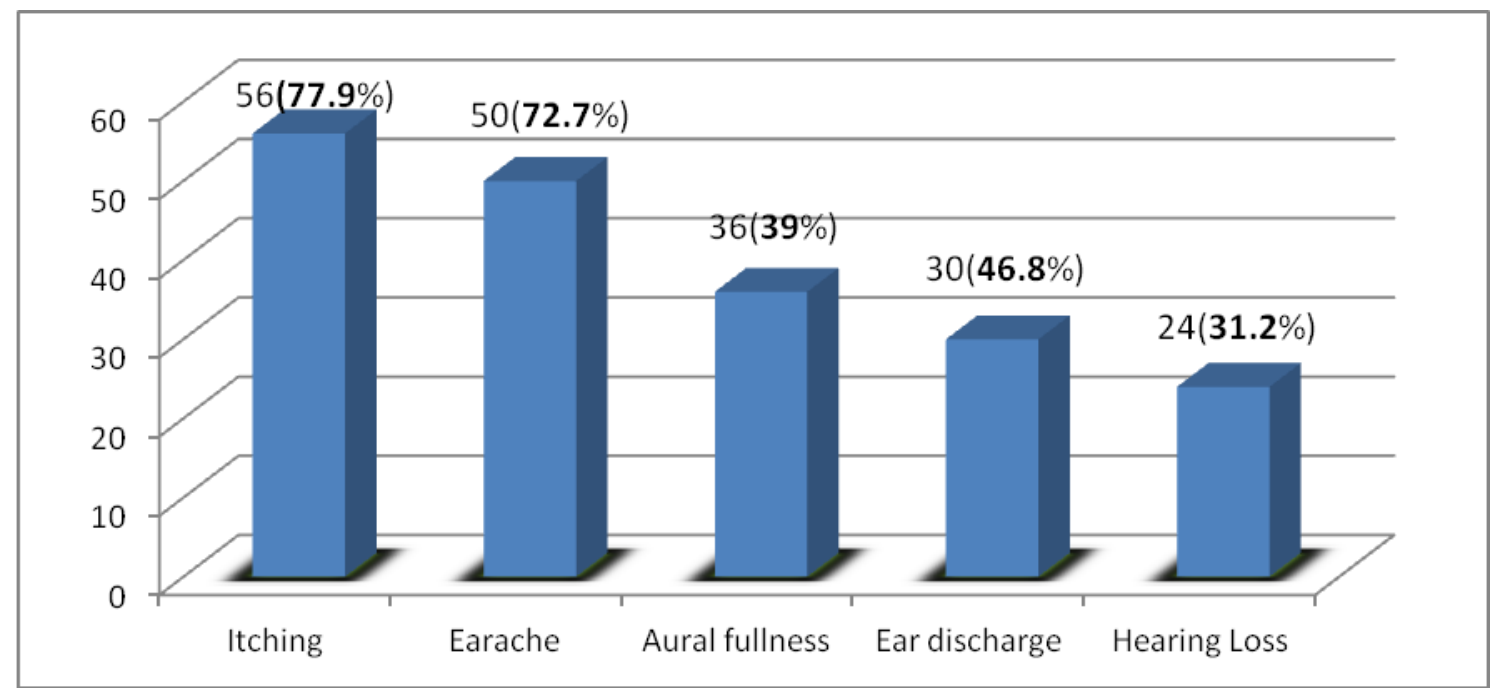

All the patients with sensorineural hearing loss were above 60 years which were most probably age related hearing loss. Out of 19 patients with conductive hearing loss 4(5.2\%) patients were having TM perforation. There wasn't any immunecompromised status.

Table 1: Type of fungal debris $(n=77)$

\begin{tabular}{|c|c|c|}
\hline Type of fungal debris & No & $\%$ \\
\hline $\begin{array}{l}\text { Blackish (Aspergillus } \\
\text { niger) }\end{array}$ & 38 & 49.4 \\
\hline $\begin{array}{l}\text { Whitish } \\
\text { (Candida species) }\end{array}$ & 27 & 35.1 \\
\hline $\begin{array}{l}\text { Yellowish } \\
\text { (Aspergillus flavus) }\end{array}$ & 12 & 15.6 \\
\hline Total & 77 & 100 \\
\hline
\end{tabular}

Type of fungal debris found is presented in table 1 . Based on type of fungal debris on otoscopy, blackish was the commonest with frequency of 38 patients (49.4\%) followed by whitish debris in 27 patients (35.1\%) and yellowish among 12 patients (15.6\%).

\section{DISCUSSION}

Andrall and Gaverret were the first to describe fungal infections of the ear [7]. Otomycosis is a superficial mycotic infection of the outer ear canal. The infection may be either subacute or acute and is characterized by inflammation, pruritus, scaling, and severe discomfort. The mycosis results in inflammation, superficial epithelial exfoliation, masses of debris containing hyphae, suppuration, and pain.

Otomycosis is the one of the commonest problem that patient present to otorhinolaryngology OPD. In the present study total of 77 patients with otomycosis were observed. This accounts for around $8.7 \%$ of total OPD cases here. The incidence is more than that of other parts of this country. This is due to higher temperature, humidity and habit of swimming in the ponds.

Regarding sex distribution $64.9 \%$ were female and $35.1 \%$ were male. This is in accordance with study done by Ahmed [8] and Aneja et al [9] but study done in Texas showing males affected more than female 
(56\% vs 44\%) [10]. Similarly study by Than et al [11] in Burma showing male affection more than female. The reason for more male affected may be due to less population of them than the female as most of male population here are abroad.

Overview of literature shows that among the fungus involved, Aspergillus niger and Candida were the most common species causing otomycosis worldwide. In this study Aspergillus niger were involved in $49.4 \%$ of the cases which correlated with Paulose et al [12] which showed 54.3\% affected with aspergillus niger. Also this study is inaccordance with Aneja et al [9] and Fasunla et al. [13] In $35.1 \%$ of cases candida species affected in this study. This was in contrast to study done by Jackman et al [14] as they found candida species as the most commonest organism. Aspergillus flavus implicated in $15.6 \%$ of the cases which was correlated with the study by Yehia et al [15]. A study by Abdelazeem et al [8] showing 9\% of cases affected with Aspergillus flavus.

Overall the most common presenting symptom was itching which was present in $77.9 \%$ of the cases. Study by Anwar et al found $77 \%$ of cases having ear pruritus [2]. Almost 93\% of cases having pruritus were found in study done by Pradhan et al [5]. Study done in Turkey showing $100 \%$ of the cases having itching [8]. Itching was followed by earche in $72.7 \%$ of cases. Study by Abdazaleem et al [8] showing only 41\% with earache. More prevalence of acute otitis externa in this study may be due to scratching of the ear secondary to severe ear pruritus.

Hearing loss was present in 24 cases(31.2\%). Among patients with hearing loss conductive hearing loss was present in 19 patients and sensorineural hearing loss in 5 patients. All the patients with sensorineural hearing loss were above 60 years which were most probably age related hearing loss. Out of 19 patients with conductive hearing loss $4(5.2 \%)$ patients were having TM perforation. The basic pathology for TM perforation is thrombosis of adjacent blood vessels leading to avascular necrosis [6]. Almost $20 \%$ of cases with TM perforation observed in study by Anwar et al [2] and Pradhan et al [5].

\section{CONCLUSION}

Otomycosis is one of commonest presenting problem in otorhinolaryngology OPD. Females are affected more. Aspergillus niger implicated the most and ear itching is the most common presenting symptom.

\section{ACKNOWLEDGEMENT}

We are grateful to all the members of Department of ENT, Janaki Medical College teaching hospital, Ramdaiya, Janakpur for their support.

\section{REFERENCES}

1. Carney A. Otitis externa and otomycosis, In: Gleeson M ScottBrown's Otorhinolaryngology, Head and Neck Surgery. CRC press book. 2008;3:pp7

2. Anwar K \& Gohar MS. Otomycosis: clinical features, predisposing factors and treatment implications. Pakistan J of med sci 2014;30(3):564.

3. Wang MC, Liu CY, Shiao AS, Wang T. Ear problems in swimmers. J of the Chinese Med Assoc 2005; 68(8): 347-352.

4. Loh K, Tan K, Kumarasinghe G, Leong H, Yeoh K. Otitis externa - the clinical pattern in a tertiary institution in Singapore. Annals of the Academy of Med 1998; 27(2): 215218.

5. Pradhan B, Tuladhar NR, Amatya RM. Prevalence of otomycosis in outpatient department of otolaryngology in Tribhuvan University Teaching Hospital, Kathmandu, Nepal. Annals of Otology, Rhinology \& Laryngology 2003; 112(4): 384-387. 
6. Kumar KR. Silent perforation of tympanic membrane and otomycosis. Indian J of otolaryng 1984;36(4):161-162.

7. Collee JG, Miles R, Watt B. Tests for identification of bacteria, In: Mackie and McCartney practical medical microbiology. 14thed. Churchill Livingstone, New York; 1996.14: pp 131-139.

8. Abdelazeem M, Gamea A, Mubarak H, Elzawawy N. Epidemiology, causative agents, and risk factors affecting humanotomycosis infections. Turkish J of med sci 2015; 45(4): 820-826.

9. Aneja K, Sharma C, Joshi R. Fungal infection of the ear: a common problem in the north eastern part of Haryana. International J of pediatric otorhinolaryng 2010; 74(6): 604607.

10. Ho T, Vrabec JT, Yoo D, Coker NJ. Otomycosis: clinical features and treatment implications. Otolaryngology--Head and Neck Surgery. 2006; 135(5): 787-791.

11. Than KM, Naing KS, Min M. Otomycosis in Burma, and its treatment. The American J of trop med and hyg 1980; 29(4): 620-623.

12. Paulose K, Khalifa S, Shenoy P, Sharma R. Mycotic infection of the ear (otomycosis): a prospective study. The J of Laryngology \& Otology 1989; 103(1): 30-35.

13. Fasunla J, Ibekwe T, Onakoya P. Otomycosis in western Nigeria. Mycoses 2008; 51(1): 67-70.

14. Jackman A, Ward R, April M, Bent J. Topical antibiotic induced otomycosis. Int $\mathrm{J}$ of pediatric otorhinolaryngology 2005; 69(6): 857-860.

15. Yehia M, Al-Habib H, Shehab N. Otomycosis: a common problem in north Iraq. The J of Laryngology \& Otology 1990; 104(05): 387-389 